\title{
Relaciones de género y condiciones laborales en el sector productivo del banano orgánico en Sullana, Piura
}

Recibido: 17/05/19

Aprobado: 04/08/19

\author{
Guiomar Vásquez Zamora \\ Universidad Nacional Mayor de San Marcos \\ guiovaz555@gmail.com
}

\begin{abstract}
RESUMEN
Desde hace 19 ańos asociaciones de agricultores de la provincia de Sullana vienen produciendo y exportando banano orgánico certificados por el Comercio Justo para Europa, Asia y Estados Unidos. En este marco contextual el presente artículo analiza cómo están cambiando las relaciones de género, expresadas en la división sexual del trabajo, si la incorporación de las mujeres al empleo asalariado del banano orgánico ha generado su empoderamiento; así como conocer si las condiciones laborales se definen por la cultura y las leyes laborales.

Este artículo presenta los resultados de la Tesis - 2016 - UNMSM, con información actualizada al 2019, denominada: Relaciones de género y condiciones laborales de trabajadores y trabajadoras del banano orgánico de los centros poblados de Huangalá y San Vicente de Piedra Rodada, Sullana, Piura, 2010-2012.
\end{abstract}

Palabras clave: Agricultura, Comercio Justo, división sexual del trabajo, género y empleo.

\section{Gender relations and working conditions in the productive sector of organic bananas in Sullana, Piura}

\begin{abstract}
For the past 19 years, associations of farmers in the province of Sullana have been producing and exporting organic bananas certified by Fair Trade for Europe, Asia and the United States. In this contextual framework, this article analyzes how gender relations, expressed in the sexual division of labor, are changing if the incorporation of women into the salaried employment of organic bananas has generated their empowerment; as well as knowing if working conditions are defined by culture and labor laws. This article presents the results of the Thesis - 2016 - UNMSM, with information updated to 2019, entitled: Gender relations and working conditions of organic banana workers in the Huangalá and San Vicente de Piedra Rodada townships, Sullana Piura, 2010-2012.
\end{abstract}

KeYwords: Agriculture, Fair Trade, sexual division of labor, gender and employment. 


\section{Introducción}

E presente artículo difunde los resultados de la tesis denominada "Relaciones de género y condiciones laborales de trabajadores y trabajadoras del banano orgánico de los centros poblados de Huangalá y San Vicente de Piedra Rodada, Sullana, Piura, 2010-2012», aprobada el año 2016 por la Facultad de Ciencias Sociales de la Universidad Nacional Mayor de San Marcos.

El distrito de Sullana, tiene un total de 136446 habitantes, siendo 65242 hombres y 71204 mujeres. El centro poblado de Huangalá tiene un total de 4671 personas, 2383 hombres y 2288 mujeres. San Vicente de Piedra Rodada tiene un total de 3245 personas, 1623 hombres y 1622 mujeres. Se trata de zonas rurales que con las secuelas positivas de la actividad económica de la exportación del banano orgánico se está avanzando en mejorar servicios considerados urbanos como la luz, el agua potable, la buena educación, viviendas dignas, trabajo asalariado y con derechos.

Dichos centros poblados se caracterizaban hasta la década del ' 90 por la agricultura familiar de subsistencia y empleo autónomo. Actualmente impulsado por el comercio internacional y políticas laborales y económicas del Estado que promueven el desarrollo rural, se viene desarrollando la agricultura de exportación no tradicional del banano orgánico, contexto económico que ha generado empleo asalariado para hombres y mujeres de zonas rurales, amparado en un régimen laboral especial de la Ley $\mathrm{N}^{\circ} 27360$ - Ley de promoción agraria que reduce a la mitad los derechos laborales y las normas internacionales de trabajo adoptadas por el Comercio Justo.

La agricultura de exportación no tradicional del banano orgánico se caracteriza por el asociativismo, tecnología en su producción para la exportación y es fuente de empleo formal y asalariada. Al 2018 se han exportado el promedio de 19, 201,148 kg de banano orgánico, 15\% de crecimiento anual (Agrodata Perú, 2019), con exportaciones totales de 160 millones de dólares (Solidaridad, 2019). El banano orgánico se exporta a son EE.UU., Bélgica y Alemania. Existen a la fecha 35 asociaciones de pequeños productores que agrupan a 8000 productores, con parcelas de $1 / 2$ a 1 hectárea. Por productor, están certificadas por el Comercio Justo y venden el banano orgánico a la empresa DOLE, principal compradora y exportadora del Perú.

Para la mayoría de mujeres es su primera experiencia laboral asalariada, motivo por el cual la pregunta orientadora del presente artículo es: ¿Cuáles son los cambios en las relaciones de género, expresadas en la división sexual del trabajo y el empoderamiento de las mujeres, así como condiciones laborales que conviven entre la formalidad y las costumbres locales?.

A partir de la pregunta general, el artículo se divide en tres (3) partes: La primera da a conocer si la incorporación de las mujeres al empleo asalariado del banano orgánico produce su empoderamiento para decidir sobre sus vidas, su familia y en el espacio laboral. La segunda da a conocer si dicha inserción laboral modifica la división sexual del trabajo en las dimensiones productivas y reproductivas. La tercera parte indaga sobre las condiciones laborales que conviven entre las prácticas consuetudinarias y las leyes laborales formales».

Sobre la justificación del artículo, desde la parte práctica, existen estudios sobre las condiciones laborales en el sector agroexportador en Ica y $\mathrm{La}$ Libertad, ello alentó a indagar sobre los cambios en las relaciones de género y las condiciones laborales que se dan en la agricultura de exportación del banano orgánico para la exportación. Desde la justificación teórica se podrá contrastar con los hallazgos la teoría y práctica de conceptos claves como género, división sexual del trabajo, empoderamiento y el enfoque del materialismo histórico como eje de análisis del trabajo agrícola.

Se ha usado la metodología de investigación social del tipo cuantitativa y cualitativa, la cualitativa es del tipo exploratorio y explicativa.

La muestra es no probabilística, del tipo intencional; se seleccionaron informantes claves como representantes sindicales y trabajadoras y trabajadoras del sector laboral del banano orgánico de las Asociaciones de productores de los Centros Poblados de Huangalá y San Vicente de Piedra Rodada. Las técnicas de recolección de información usadas son: La entrevistas en profundidad, 20 en total, cuya información se ha procesado con el programa Atlas Ti. Asimismo, se han realizado 100 encuestas de opinión para cuantificar los resultados. Se ha procesado la información con el programa estadístico SPSS V19. 


\section{Resultados}

Para analizar los resultados se han considerado necesario citar los siguientes conceptos: Género, división sexual del trabajo, empoderamiento y el enfoque del materialismo histórico.

El género como categoría de análisis es un elemento constitutivo de las relaciones sociales basadas en las diferencias entre los sexos, por la cual se asignan roles, acceso al espacio público y privado, define condición y posición social de mujeres y hombres. El género está constituido por 4 dimensiones o elementos interrelacionados en los que se expresa y reproducen los símbolos, conceptos normativos, lo político-social-institucional y la identidad subjetiva. (Scott, 1996, p. 2).

Según la misma autora, se interpretan a continuación las 4 dimensiones de género:

- Dimensión simbólica, referida a las interpretaciones de cómo deben ser hombres y mujeres a partir de las ideas, creencias y el imaginario social presentes en cada cultura de una sociedad. Por ejemplo la idea de que la jefatura y representación del hogar debe estar a cargo del hombre, al igual que los cargos de jefatura en los centros de trabajo.

- Dimensión normativa, referido a cómo deben ser hombres y mujeres y la relación entre ambos desde lo normado por las instituciones presentes en cada sociedad, como la iglesia, los centros educativos, la iglesia, el Congreso de la República entre otras.

- Dimensión política, social e institucional, incluye las dos (2) dimensiones anteriores poniendo en evidencia cómo se organiza la sociedad desde la división sexual tanto en las instituciones formales y no formales como la familia, medios de comunicación, sindicatos, partidos políticos, las empresas y organizaciones diversas. Por ejemplo en zonas rurales la prioridad de que los hijos hombres accedan a la educación. El acceso a cargos directivos en los sindicatos, los partidos políticos y las empresas. Así como prácticas laborales influenciadas por la cultura como el hostigamiento sexual y la discriminación a las mujeres embarazadas.
- Dimensión subjetiva, referida a la autopercepción que construye la identidad de hombres y mujeres, influenciada por la cultura, los símbolos y las normas. Por ejemplo, si bien una mujer ha logrado el éxito profesional, la cultura le va hacer sentir incompleta, el mandato de género es que deber ser madre y esposa. Otras identidades construidas son: mujer delicada y sumisa y hombre fuerte $y$ autoritario.

Resumiendo las 4 dimensiones se puede observar en el gráfico 1: En la base los símbolos, valores y creencias propios de la cultura, en el centro las normas formales y consuetudinarias aplicadas por las instituciones y en la cima la dimensión subjetiva que determina la identidad de género.

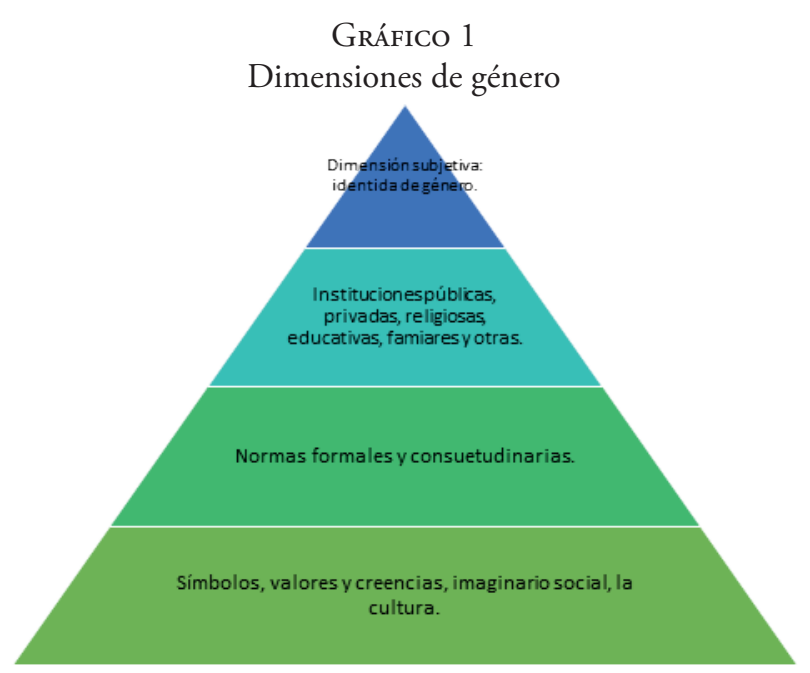

Fuente: Scott, 1996, pág. 2. Elaboración propia.

La división sexual del trabajo, es parte de la categoría de análisis de género, es parte constitutiva de las relaciones sociales de toda sociedad: «El espacio público reservado para la producción y para el hombre y el privado destinado a un trabajo reproductivo o de procreación, consignado a las mujeres» (Scott, 1996, p. 3). La misma autora citando a Bordieu, P. señala que «la división del trabajo de producción y reproducción y toda la organización de la vida social establecen distribuciones de poder expresados en el acceso y control de recursos materiales y simbólicos». Otros autores señalan que la división sexual del trabajo identifica 3 espacios para hombres y mujeres: El trabajo productivo, reproductivo y el comunal. (Escuela para el Desarrollo, 2006, p. 30). 
El empoderamiento, señala que "consiste en dotar a las mujeres de mayor poder y control sobre sus propias vidas, implica la concientización, confianza en sí mismas, más oportunidades y un mayor acceso a los recursos y control de los mismos. El empoderamiento surge del interior, depende de ellas» (Unión Mundial para la Naturaleza, 1999, p. 31).

El enfoque del materialismo histórico, el cual aduce que los fenómenos sociales tienen su origen en causas económicas, señala las siguientes categorías de análisis presentes en toda sociedad: «La propiedad privada, la división del trabajo, la contradicción entre capital y trabajo y su relación de conflicto permanente (burguesía y proletariado), las clases sociales tales como fuerza laboral y empleadores, y la plusvalía» (Porras, 2004, p. 66).

\section{Incorporación de las mujeres al empleo asalariado del banano orgánico}

Según los resultados de la tesis, el perfil de la fuerza laboral del sector agrario del banano orgánico es la siguiente: Población joven, de estado civil convivientes, casados y madres solteras, con secundaria completa, vivienda propia, el 40\% tienen de 6 años a más laborando en las asociaciones del banano orgánico. Los hombres tienen a la pequeña agricultura como actividad complementaria y las mujeres la venta de licores, crianza de animales, venta de comida y chicha.

Según la OIT y la CEPAL el crecimiento del empleo femenino en Latinoamérica, se puede explicar por los siguientes factores:

- «Flexibilización del mercado laboral (permite contratar y despedir con facilidad)

- Demanda de trabajo fino en actividades de exportación no tradicional, especialmente textiles y agroindustria.

- Paulatino aumento de los niveles educativos de las mujeres, especialmente jóvenes.

- Descenso de las tasas globales de fecundidad, de 4,3 hijos en 1986, a 2,9 hijos en el 2000.

- Los profundos cambios en las estructuras y composiciones de los hogares.

- El incremento de la jefatura familiar femenina, emancipación de las mujeres.

- La crisis económica y sus consecuentes bajas de ingresos». (OIT, 2007, p. 53).
Según los hallazgos de la tesis, la inserción de las mujeres al empleo asalariado del banano orgánico, coincide con algunos de los factores identificados por la OIT, tales como: Demanda de sus habilidades manuales para la agroindustria, madres solteras, menores tasas de fecundidad, factores económicos, cambios en la organización productiva, al pasar de agricultura familiar a asociaciones de productores, este cambio ha generado empleo asalariado dependiente y con acceso a derechos laborales.

El ingreso de las mujeres al empleo asalariado significa el cambio de posición social, ahora forma parte de la fuerza de producción asalariada, tiene derechos laborales y ha ingresado al espacio público, sin embargo en el espacio familiar el orden jerárquico se mantiene, ubicando a las mujeres como responsables del trabajo del cuidado y el trabajo asalariado por tanto sigue siendo complementario. Las mujeres solteras han mejorado su poder de compra, tienen bienes muebles e inmuebles adquiridos por la retribución de su trabajo asalariado del banano orgánico.

Según los resultados de la tesis, las causas de inserción de las mujeres al empleo asalariado se debe principalmente a factores de nupcialidad y necesidades económicas propias de las responsabilidades familiares que asumen al formar familia, por ello el $20 \%$ de hombres y $10 \%$ de mujeres confirman que buscaron el empleo en el sector bananero para «apoyar a su familia, hijos y esposo» (ver Gráfico 1).

Sin embargo se ha identificado en las entrevistas que en general la actitud de los hombres frente a la incursión de las mujeres al empleo asalariado lo consideran como "no es necesario» (Vásquez, 2017), lo cual refuerza el rol de proveedor de los hombres y el trabajo reproductivo asignado a las mujeres.

Asimismo la incursión de las mujeres al empleo asalariado del banano orgánico, ha evidenciado el triple rol de las mujeres - trabajo productivo, reproductivo y comunal- y ante la inexistencia de regulación legal de corresponsabilidad del trabajo reproductivo, es la familia extendida, como madres, hermanas y suegras quienes realizan el trabajo del cuidado de los hijos, personas mayores y enfermos, así como las múltiples labores domésticas.

Considerando el «Diamante del Bienestar» propuesto por Latindadd, el cual plantea que la solución para la tensión entre el trabajo productivo y reproductivo es la conciliación y la corresponsabilidad. 
GráFICO 1

Causas del empleo asalariado de las mujeres

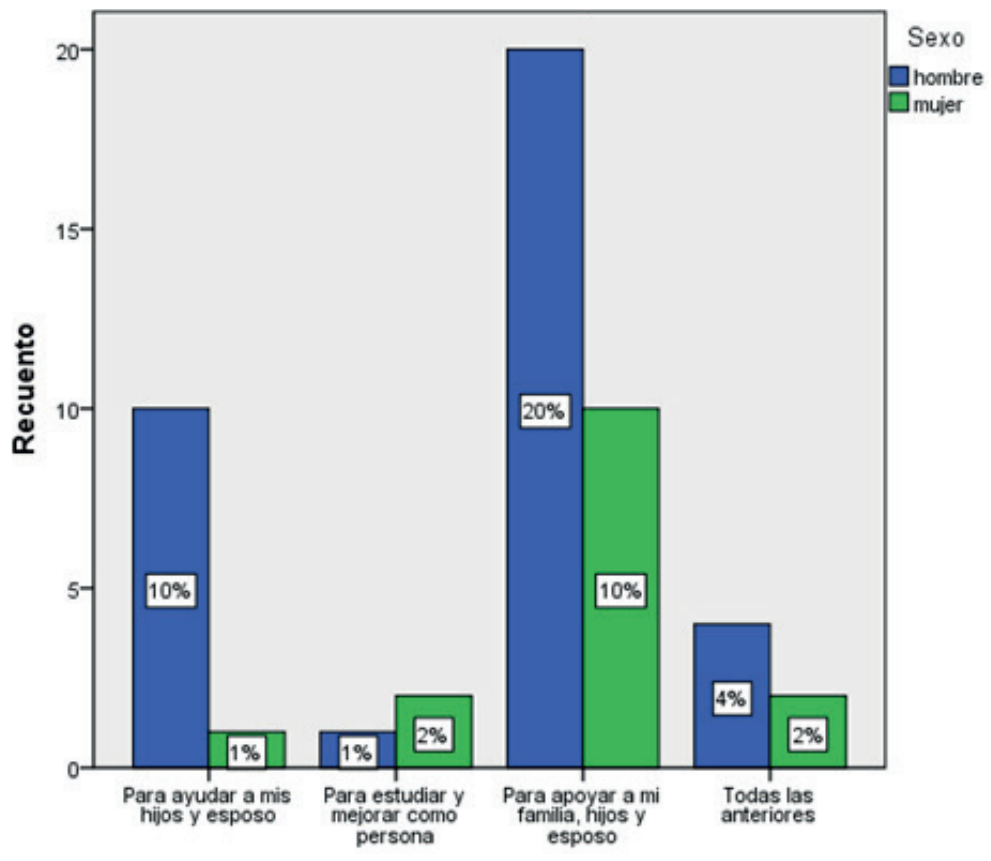

Fuente: Elaboración propia en base a encuestas de la muestra de la investigación. 2013
- El trabajo familiar no remunerado es asumido por el $17.7 \%$ de mujeres y el $6.4 \%$ de hombres,

- Las horas de trabajo remunerado es de 36 horas para las mujeres y 50,4 horas para los hombres.

- Las horas de trabajo doméstico no remunerado es de 39.5 horas para las mujeres y 15.9 horas para los hombres.

Así encontramos que los hallazgos de la tesis son similares, el trabajo doméstico no remunerado es exclusivo para las mujeres, en zonas rurales este se incrementa debido al cuidado de animales menores, recojo de agua, entre otras laborales propias del campo, el toral de horas dedicadas a las labores domésticas es de hasta 4 horas diarias para las mujeres con responsabilidad familiar y si son mujeres solteras de 2 horas diarias. El 60\% de hombres y mujeres afirman que son las mujeres en

La primera plantea trabajos de medio tiempo, los descanso pre y post natal y horarios flexibles para el cuidado familiar, en concreto sería las que seguirían asumiendo el trabajo reproductivo. Este modelo se viene cumpliendo en el sector laboral del banano orgánico, a través del descanso pre y post natal y la hora diaria de lactancia. "La corresponsabilidad, asume que tanto el cuidado familiar y laboral forman un solo sistema, por tanto la solución implica responsabilidad compartida, es decir involucra a las empresas, al Estado, a los trabajadores y trabajadoras». (Red Latinoamericana sobre Deuda, Desarrollo y Derechos - LATINDADD. García D. y Salamanca, R., 2012, pág. 7).

\section{División sexual del trabajo en las dimensiones productivas y reproductivas}

El indicador principal de la división sexual del trabajo identificados por la Encuesta Nacional del Uso del Tiempo, es el tiempo de trabajo dedicado al trabajo doméstico no remunerado, así los datos son los siguientes: (INEI - ENUT, 2015) este caso, las esposas, madres y suegras responsables de las labores del hogar. El 22\% de hombres y mujeres comparten labores del hogar y el 14\% de hombres consideran que su trabajo es solo en las plantaciones del banano orgánico. Por tanto, si bien la mujer ha ingresado el mercado laboral el trabajo de cuidado sigue siendo su responsabilidad principal, no ha cambiado los roles de género asignados por la cultura y sociedad. (Vásquez, 2017, p. 201)

Según los testimonios de las entrevistas hay evidencias que refuerzan la división sexual del trabajo, en los centros laborales el atributo de autoridad es para hombres, refuerzo de ideas y creencias del atributo de belleza de las mujeres, obviando su rol laboral de asalariada y respeto de sus derechos laborales como la prevención y sanción del hostigamiento sexual.

El supervisor ve el avance del trabajo, si hay avance le dan más trabajo. Todos los supervisores son hombres, porque son los que mandan más, son más estrictos, a la mujer no le respetan, porque ha habido mujeres como supervisoras, pero no la respetan y el trabajo no avanzaba. También hay un caso que el supervisor se enamoró de una trabajadora y ella no le hacía caso y se molestaba con todos los trabajadores/as». (Entrevista 1, mujer, 
36 ańos, trabajadora de la $\mathrm{ASPBOH}$, setiembre 2013). (Vásquez, 2017, p. 148)

Otra evidencia de la división sexual del trabajo, por tanto del trabajo productivo y reproductivo, está asociado con su menor participación en el centro de trabajo y con ello la mínima afiliación sindical de las mujeres en el sindicato. Así en la producción del banano orgánico en cada empacadora, de 18 trabajadores, 2 son mujeres. Las funciones asignadas a las mujeres son la limpieza o fumigado y el seleccionado de la fruta. Funciones como el de supervisor y jefe de cuadrilla son hombres, así como labores que demandan uso de la fuerza física se les asignan a los hombres.

\section{Condiciones laborales: Tensión entre las leyes y las costumbres}

Es importante relatar el origen de las asociaciones de productores del banano orgánico, son herederos de la reforma agraria, en dicho momento eran cooperativas agrarias y el trabajo asalariado era "golondrino", familiar y no asalariado. Las cooperativas culminan su gestión y las tierras se dividieron en parcelas, estas a su vez con el incremento de la población, las familias han transferido a sus hijos las parcelas, subdividiéndose aún más. Las asociaciones nacen en el año 2000 producto del programa del Estado para la siembra del banano orgánico para la exportación y asociatividad de los pequeños productores.

Entonces esta nueva modalidad de producción agrícola ahora contrata fuerza laboral formal asalariada y con derechos, dichas asociaciones tienen antecedentes culturales propios de la gestión de las cooperativas, y si bien en su momento fueron prácticas sociales aceptadas, estas se han visto cuestionadas con la dación de normas formales que regulan el empleo como la Ley N² 27360 - Ley de Promoción Agraria y el trabajo decente propuesto por la OIT y adoptado por el Comercio Justo como indicador de comercio que respeta derechos laborales y mejora condiciones de vida de productores y fuerza laboral agrícola.

La fuerza laboral se organiza en cuadrillas, así le denominan al grupo de 18 trabajadores, 16 hombres y 2 mujeres, encargados de la cosecha y empaque del banano orgánico de un sector de los campos de cul- tivo. Cada Asociación de Productores puede tener hasta 12 cuadrillas dependiendo de la cantidad de contenedores solicitados para exportar. Lo cual indica que un pequeño productor puede tener hasta 216 trabajadores y trabajadoras.

Las Asociaciones están organizadas en 3 grados o niveles, en el primer grado están las asociaciones independientes y pueden llegar hasta 40 productores, en el segundo grado se agrupan las asociaciones con personería jurídica con más de 40 productores y en el $3^{\circ}$ grado agrupa a asociaciones que integra a 1286 productores como es el caso de CEPIBO, «con 12 asociaciones, con cultivo de 1352 ha de banano orgánico, ocupa el segundo en las exportaciones de banano orgánico a nivel nacional». (CEPIBO, 2019)

El sector del banano orgánico está regulado por las normas nacionales y normas internacionales adoptadas como parte del Comercio Justo, las cuales se describen a continuación.

La Ley $\mathrm{N}^{\circ} 27360$ ley de promoción agraria $20 / 10 / 2000$, se caracteriza por otorgar la mitad de derechos laborales comparado con otros regímenes laborales del sector privado. Otorga 15 días de vacaciones, jornadas acumulativas (más de 8 horas diarias pero no mayor a 48 horas semanales), la remuneración incluye la CTS y las gratificaciones y aporte del empleador del $4 \%$ a Essalud.

El año 2007, el Colegio de Abogados de Ica, presentó la demanda de inconstitucionalidad de la Ley 27360, aduciendo su fin discriminatorio para la fuerza laboral del sector agrario. Según el fallo del Tribunal Constitucional - TC sobre la Constitucionalidad de la Ley $\mathrm{N}^{\circ}$ 27360. Expediente $\mathrm{N}^{\circ}$ 00027-2006-PI (21/10/2007), niega el carácter discriminatorio de dicha norna dado el carácter informal en el sector agrario y la necesidad de fomentar su desarrollo, expone los siguientes argumentos:

Para el TC, las diferencias de trato legislativo se justifican en el artículo $103^{\circ}$ de la Constitución Política del Perú, que faculta a legislar de manera especial y excepcional, cuando la naturaleza de las cosas así lo amerite, y no por cuestiones arbitrarias o infundadas. En el caso del régimen agrario, las particularidades del mercado de trabajo en el sector, caracterizado por la temporalidad, aleatoriedad, movilidad, estacionalidad, informalidad y dificultad en el acceso al empleo justifican un trato excepcional y especial. Además, la propia 
Constitución les impone al Estado dos obligaciones: i) promover condiciones para el progreso social y económico, mediante políticas de fomento del empleo productivo; y, ii) dar apoyo preferente al desarrollo agrario. Estos preceptos, justificarían también una regulación específica orientada al cumplimiento de esto deberes. (Vásquez, 2017, p. 46)

El comercio justo, tiene como objetivo repartir las ganancias para toda la cadena de producción y comercialización pero verificando con auditorias sociales se cumplan los estándares laborales y ambientales. Para el caso del sector bananero el reparto es de $\$ 1.00$ por caja vendida en Europa, dicho dinero debe ser usado para mejoras de la comunidad. Los estándares laborales se rigen por los objetivos del trabajado decente de la OIT, tales como: Derechos fundamentales de los trabajadores (Libertad sindical, no al trabajo forzoso y al trabajo infantil, no discriminación laboral), protección social, diálogo social y la igualdad de género. Flo Fairtrade es una certificadora del Comercio Justo del banano orgánico, mediante auditores sociales verifica el incumplimiento laboral y ambiental (uso de abonos no permitidos), se restringe las exportaciones a Europa y en general se mancilla la imagen de la producción del Perú.

Considerando el marco normativo que regula el sector bananero, se tiene los siguientes resultados: El derecho laboral con mayor porcentaje de incumplimiento es la jornada laboral, es así que el $76 \%$ de entrevistados dijo que trabaja más de 8 horas diarias. El 4\% tiene contrato temporal pese a que el banano orgánico se produce durante todo el año. 40\% desconoce la Ley No 29783 - Seguridad y salud en el trabajo. Sobre la afiliación sindical, el $48 \%$ no se afilia al sindicato por temor al despido. El $96 \%$ afirma que no se dan despidos por maternidad. Sobre el hostigamiento sexual, el 66\% afirma que no han ocurrido casos en su centro de trabajo, el 30\% afirma que si existen casos pero no se denuncian. (Vásquez, 2017).

El Sindicato de Trabajadores Agrarios del Perú SITAG Perú, es el sindicato de rama, es la mayor representación sindical en el sector bananero, tiene un total de 4000 afiliados y afiliadas. Uno de sus primeros logros ha sido el pago devengado de horas extras, feriados y dominicales acerca de 3000 trabajadores/as.
Se han identificado testimonios sobre maternidad y afiliación sindical de las mujeres que refuerzan los roles de género y espacios de participación de las mujeres, lo cual es avalado por las creencias, actitudes e imaginarios sociales presentes en la cultura local y en la parte empleadora. Se describen los siguientes testimonios al respecto:

Las mujeres que están embarazadas ya no trabajan, se van del trabajo, porque es peligroso para la mujer y el niño, además hay que estar paradas todo el día, a veces hasta las 6 de la tarde. (E10, M, 28 años, 2015)

Las mujeres es difícil que se afilien al sindicato, si cuando se inició el sindicato habían buenas mujeres, estaban en la marcha, en la olla común, pero después se fueron. Una vez teníamos que llevar la participación de una mujer a Costa Rica, pero fue difícil, tuvimos que pedir permiso a su esposo, de otra mujer tuvimos que pedir permiso a su papá, es difícil que participen, pero ahí seguimos insistiendo, tenemos Secretaría de la Mujer que está trabajando para que más mujeres participen. (E1, H, SITAG Perú, 50 años, 2015).

Entonces se concluye en este acápite que las condiciones laborales en el sector bananero conviven entre prácticas consuetudinarias y las leyes laborales formales. «Existe el $80 \%$ de brecha entre el cumplimiento de las normas laborales formales y las normas culturales en el espacio laboral» (Vásquez, 2017), esto puede explicarse por las características del sector productor, la cual como se explicó líneas arriba, pasó de agricultura familiar a asociación empresarial, este paso automático no ha previsto la base de todo sistema social, la parte cultural, por ello la tensión entre lo normado y las costumbres locales, así como el conflicto propio de las relaciones laborales.

Al 2019, como un medio para prevenir y dar solución oportuna a los conflictos laborales mediante el diálogo se ha firmado Convenio Macro, firmado el 15.08.2016, integran dicho acuerdo: Siete (7) asociaciones y cooperativas de pequeños productores de banano orgánico de Sullana Piura certificadas por el Comercio Justo (FLO), la Coordinadora Nacional de Pequeños Productores de Comercio Justo del Perú (CPCJ), el SITAG Perú, la COLSIBA y BANANA LINK. Dicho convenio se materializa en la Mesa 
de diálogo del Convenio Macro, los logros desde su creación son convenios colectivos y soluciones preventivas de conflictos laborales, reduciendo costos económicos, de tiempo y de imagen negativa de los empleadores certificados por el Comercio Justo, lo cual es beneficioso para la venta en el mercado europeo.

\section{Discusión}

Los hallazgos de las tesis vertidas en el presente artículo coinciden con el concepto de género propuesto por J. Scoott, tal como se menciona en los resultados, se ha evidenciado roles específicos para las mujeres, en los espacios público y privado, si bien las mujeres han ingresado al mercado laboral asalariado del banano orgánico, tienen funciones específicas y reducida participación (16 hombres y 2 mujeres por cuadrilla) y posición en el espacio laboral, solo los hombres llegan a cargos de jefatura. Hay interrelación de los 4 elementos de género que se conjugan para mantener el orden de género, tales como los símbolos, las normas formales y consuetudinarias, las normas familiares que fundamentan el espacio privado como prioridad para las mujeres, así como identidades de género que mantienen los mandatos de género.

Asimismo los resultados de la tesis presentados en este artículo son similares a tres (3) elementos claves del género como parte del sistema social, como son las actitudes, las creencias y los imaginarios, estos elementos son parte de las raíces o la base del sistema, donde se ubican los valores y las creencias presentes en el imaginario social presentes en la cultura de una sociedad.

Las actitudes "contienen un componente afectivo, surgen a partir de la evaluación de los comportamientos, sujetos, etc., las cuales orientan a realizar determinadas acciones». (INEI - ENARES, 2015-2017, p. 84). Sobre las creencias son "cogniciones, conocimientos o informaciones de los sujetos que poseen sobre un objeto actitudinal, que se expresan en proposiciones simples, conscientes o inconscientes, inferidas de lo que las personas dicen o hacen" (INEI-ENARES, 2015-2017, p. 81). Sobre los imaginarios, se trata de «relatos que están objetivamente presentes en los medios a través de los cuales la sociedad representa y hace circular los significados y valoraciones que atribuye por ejemplo a las diferencias sexuales o generacionales», "es la parte "objetiva» de la cultura, existen independientemente del uso que le dan las personas. (INEI - ENARES, 2015-2017, p. 87).

Estos tres (3) elementos han sido medidos por la Encuesta Nacional de Relaciones Sociales (ENARES), la cual mide la tolerancia social frente a la violencia contra las mujeres y los integrantes del grupo familiar.

Los resultados son los siguientes: (INEI - ENARES, 2015-2017):

En actitudes: El 34,9\% de mujeres no debe tomar decisiones sin el permiso del esposo o pareja.

\section{En creencias:}

- El 56,3\% cree que es el esposo o pareja, el que siempre debe ser el jefe del hogar o quien representa a su familia.

- El 54,7\% cree que toda mujer debe cumplir primero con su rol de madre, esposa o ama de casa y después realizar sus propios sueños.

- El 46,2\% cree que en todo hogar se necesita de un hombre para que ponga orden y disciplina.

- El 45,4\% cree que desde muy niñas las mujeres deben aprender a ser pacientes, comprensivas y complacer a sus esposos o parejas en todo.

- El 37,6\% cree que cuando la mujer sale de casa descuida sus labores en el hogar.

- El 36\% cree que el esposo o pareja es quien debe tomar las decisiones más importantes en el hogar.

\section{En imaginarios:}

- El 55,7\%, considera que el amor y paciencia de las mujeres, tarde o temprano hará que su pareja deje de ser violento.

- El 44,3\%, considera que las mujeres que descuidan a sus hijos merecen tener alguna forma de castigo por su esposo o pareja.

Otro concepto analizado complementario al tema de género es el empoderamiento de las mujeres, según los resultados de la tesis corresponde con el concepto de empoderamiento planteado por Alfaro, 1999, en cuanto al acceso y control de los recursos, pero no 
GRÁfICO 2

Tiempo de trabajo de las mujeres y distribución de ingresos mensuales.

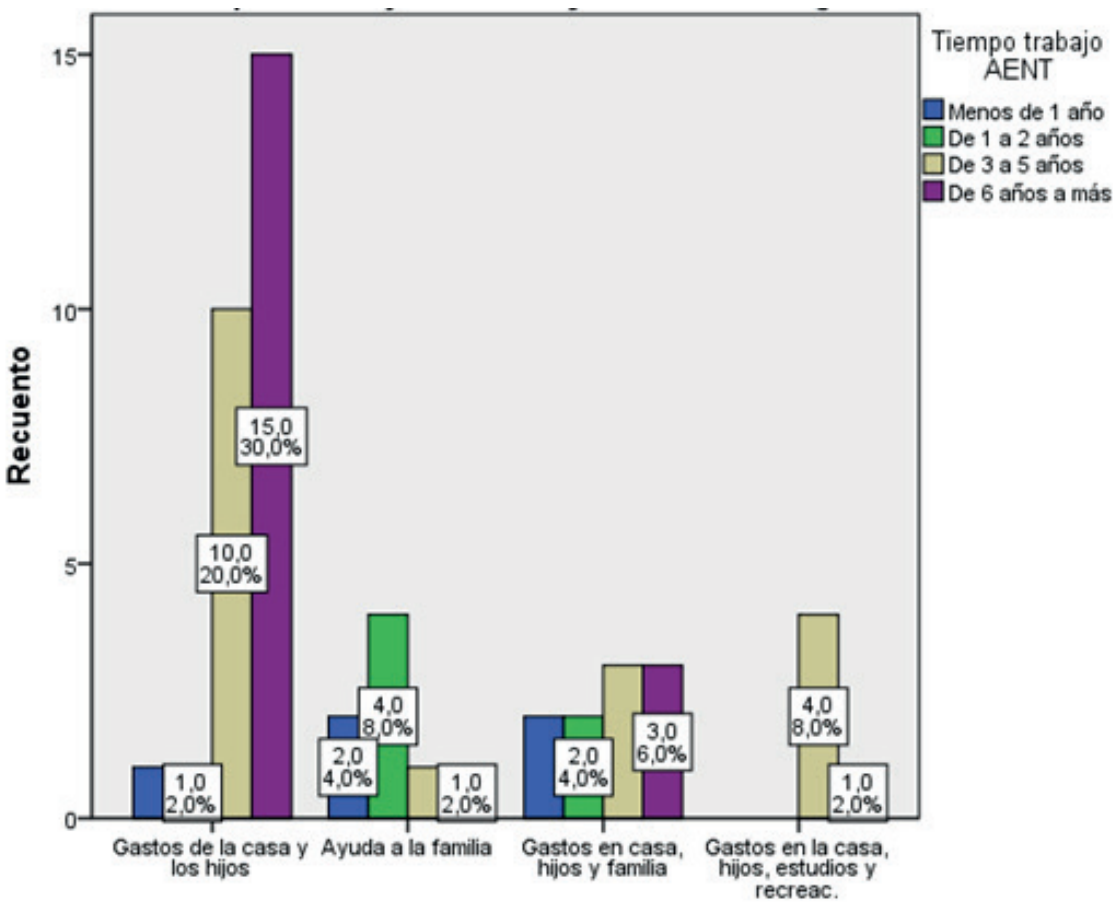

Fuente: Elaboración propia en base a encuestas de la muestra de la investigación. 2013

Este resultado coincide con la creencia mencionada líneas arriba de la ENARES, donde se considera que «toda mujer debe cumplir primero con su rol de madre, esposa o ama de casa y después realizar sus propios sueños».

Sobre la división sexual del trabajo, se ha encontrado que la incursión de las mujeres en la actividad del banano orgánico no ha modificado la división sexual del trabajo expresado en el trabajo reproductivo y productivo. «El $22 \%$ de entrevistados y entrevistadas que tienen de 3 a 5 años laborando en el banano orgánico y el $8 \%$ que tienen menos de 1 año y de 1 a 2 años en el mismo sector laboral confirma que el trabajo reproductivo lo hacen las esposas, mamás y suegras.

en cuanto al poder y control personal, las mujeres han logrado acceder al empleo asalariado del banano orgánico, pero el uso de su dinero es para la familia y no en su desarrollo personal. Según el resultado obtenido se concluye que «las mujeres con 6 a más años de trabajo destinan el 30\% de sus ingresos a gastos de la casa e hijos, del mismo modo los que tienen de 3 a 5 años laborando con el 20\%». (Vásquez, 2017) (ver Gráfico 2).

Las mujeres solteras a diferencia de las que tienen responsabilidad familiar, si han logrado empoderamiento en sus tres (3) acepciones, acceso, control y poder personal, bajo este concepto han logrado propiedades muebles e inmuebles y tienen más probabilidad de participar en espacios de capacitación y aprendizaje.
Asimismo el $12 \%$ señala que los hombres solo trabajan en el banano orgánico y no hacen ninguna labor en el hogar. Es menor la participación de hombres y mujeres que compartan el trabajo de la casa». (Vásquez, 2017) (ver Gráfico 3).

\section{GrÁFICO 3}

Tiempo de trabajo en el banano orgánico y tares en el hogar por género

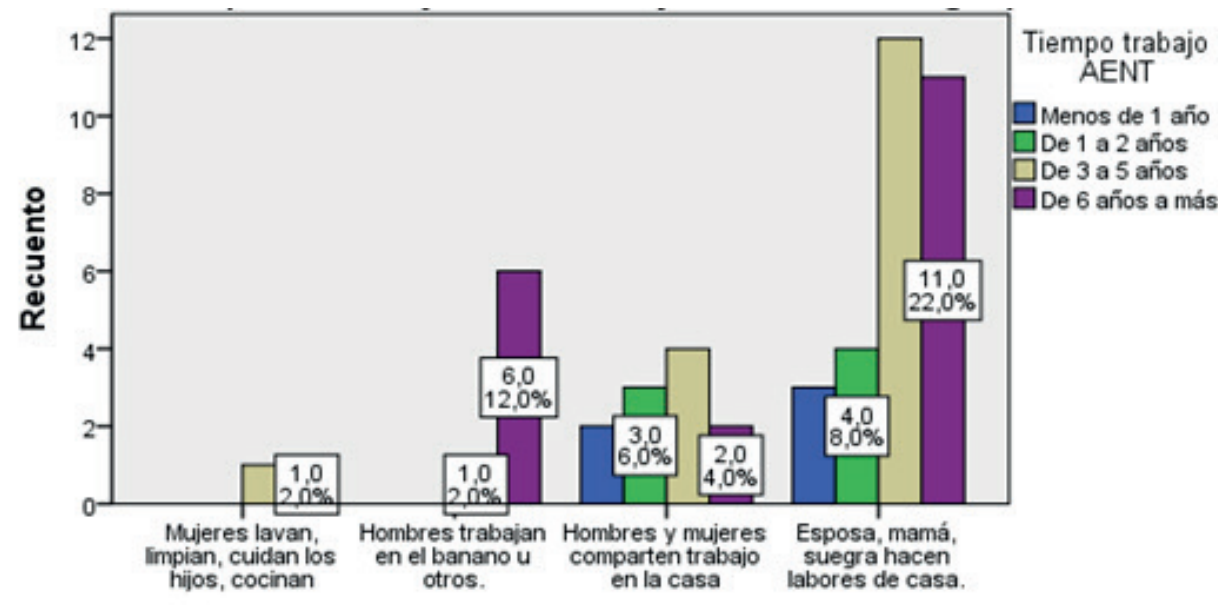

Fuente: Elaboración propia en base a encuestas de la muestra de la investigación. 2013 
Igualmente la división sexual del trabajo es parte de la organización del trabajo del banano orgánico. Las funciones más importantes se designan a los hombres y las asociadas al cuidado del producto se designan a las mujeres. La afiliación sindical igualmente tiene menos participación femenina pues al tratarse de espacio público es un espacio masculino.

La división sexual del trabajo tiene similitud con las "creencias» medidas por la ENARES, es específico con la creencia que "cuando la mujer sale de casa descuida sus labores en el hogar», en todo hogar se necesita de un hombre para que ponga orden y disciplina. (INEI-ENARES, 2015-2017).

Sobre las condiciones laborales, el paso de organización familiar a asociación, coincide con los postulados del Materialismo Histórico, pues los cambios sociales han sido originados por causas económicas, propiedad privada pero con una peculiaridad es empleador con vínculo familiar, lo cual genera fuerza laboral asalariada, peculiaridad que genera tensión para el acceso a otros derechos como la libertad sindical, los derechos laborales de las mujeres y la exigencia de otros derechos laborales, hay relación de conflicto permanente, así como plusvalía generada en parte por la Ley 27360 que reduce a la mitad los derechos laborales.

\section{Conclusiones}

El acceso al empleo asalariado no ha cambiado totalmente la posición de las mujeres, pero si ha mejorado la condición de las mismas. Un indicador es el acceso a la vivienda propia, pero falta superar brechas de género como la educación de calidad, la mayor participación de las mujeres en el empleo y espacios públicos como el sindicato.

Sobre el empoderamiento, igualmente si bien hay cambios en el acceso al empleo asalariado, el control y el poder aún obedece al orden de género normado por los elementos simbólicos e institucional, por la cual las mujeres priorizan el uso de su salario para la familia y no para su desarrollo personal.

Sobre la división sexual del trabajo, si bien la inserción de las mujeres al empleo no ha generado cambios en la asignación del trabajo reproductivo para las mujeres y del productivo para los hombres, se ha evidenciado el triple rol de las mujeres, explicado esto por las creencias y el imaginario social base del sistema social de género, esto se refuerza con la ausencia de normas formales que no facilitan la "corresponsabilidad» en el cuidado, que termina reiterando el rol de cuidado asignado a las mujeres y no como responsabilidad compartida del Estado y la parte empleadora. Esta realidad de la división sexual del trabajo puede generar discriminación en el acceso a cargos de mayor jerarquía en el centro de trabajo, cargos de jefatura asignadas a los hombres netamente, esto es reforzado por los atributos y roles de género que impiden el ascenso laboral de las mujeres; así como la menor participación sindical de las mujeres.

Se concluye que para fomentar cambios en las relaciones de género se tiene que tener en cuenta las 4 dimensiones de género propuestas por Scott, J. mencionadas en la parte conceptual de los resultados, tales como: Los símbolos, conceptos normativos, lo político-social-institucional y la identidad subjetiva; es decir dichos cambios no van a ser posibles si no consideramos la base del sistema social, como lo son los símbolos expresados en ideas, creencias y los imaginarios sociales sobre los hombres y las mujeres. Asimismo considerar la interrelación de los 4 elementos es clave para entender las relaciones de género y accionar para cambiar situaciones que pueden causar discriminación y desigualdad entre hombres y mujeres.

A diecinueve (19) años de haberse instalado la producción del banano orgánico, con ello la generación de empleo asalariado y en especial la inserción laboral para las mujeres, se han empezado a cuestionar prácticas de género, por tanto los resultados sobre las relaciones de género no son desalentadores si es que las comparamos con las proyecciones estadísticas del Informe Global sobre la Brecha de Género 2018, que «calcula 200 años para cerrar la brecha global de género, la paridad política se va lograr en 107 años, el empoderamiento económico en 202 años y la brecha de género en educación podría cerrarse en 14 años, principalmente el analfabetismo femenino». (Foro Económico Mundial, 2018).

Sobre las condiciones laborales, si bien el paso de agricultura familiar a asociación empresarial fue importante, existe tensión permanente entre los derechos laborales formales y los consuetudinarios. Existen dos (2) instrumentos para el ejercicio de los derechos laborales, la Ley 27360 - Ley de Promoción 
Agraria y los principios del trabajo decente adoptadas por el Comercio Justo, estás última otorga premio de $\$ 1.00$ por caja exportada para mejorar condiciones de vida de productores y fuerza laboral, asimismo al no cumplir con las normas internacionales se suspende la exportación del banano orgánico, esto perjudica a los productores peruanos en general.

La producción del banano orgánico se organiza según el modelo Fordista, es decir se trata de trabajo mecánico y producción estandarizada. Sostiene la mano de obra los salarios fijos y bonos por productividad, el año 2017 han llegado a S/ 4.50 a partir de las 220 cajas, considerado el más alto de la zona productora de Sullana, así como estabilidad laboral debido a la actividad bananera que produce los doce (12) meses del año.

\section{Bibliografía}

Agrodata Perú (23 de enero de 2019). www.agrodataperu.com. Obtenido de www.agrodataperu.com: https:// www.agrodataperu.com/2019/01/platano-banano-peru-exportacion-2018-diciembre.html

CEPIBO (2019). www.progreso.org.pe. Obtenido de www. progreso.org.pe: https://www.progreso.org.pe

Escuela para el Desarrollo (2006). Curso-Taller: Género, identidad y cultura. Lima.

Foro Económico Mundial (22 de diciembre de 2018). www.bbc.com. Obtenido de www.bbc.com: https:// www.bbc.com/mundo/noticias-46638119

INEI-ENARES (2015-2017). www.inei.gob.pe. Obtenido de www.inei.gob.pe: https://www.inei.gob.pe/media/
MenuRecursivo/publicaciones_digitales/Est/Lib1390/ libro.pdf

INEI-ENUT (2015). www.inei.gob.pe. Obtenido de www. inei.gob.pe: www.inei.gob.pe

OIT (2007). Panorama Laboral . Lima.

Porras, R. (2004). Compilación de teoría sociólogica - Marx, K. El materialismo dialéctico. En R. Porras, Compilación de teoría sociólogica - Marx, K. El materialismo dialéctico (pág. 66). Lima - Perú: UNFV.

Red Latinoamericana sobre Deuda, Desarrollo y Derechos - LATINDADD. García D. y Salamanca, R. (2012). Por qué lo económico es vital y lo vital no es importante. Colombia.

Scotт, J. (1996). PUCP. Género, conceptos básicos. El género una categoría útil para el análisis histórico. Lima.

SOLIDARIDAD (15 de febrero de 2019). www.solidaridadsouthamerica.org. Obtenido de www.solidaridadsouthamerica.org: https://www.solidaridadsouthamerica.org/ es/news/per\%C3\%BA-proyecto-cl\%C3\%BAster-debanano-org\%C3\%A1 nico-liderado-por-solidaridadimpulsar\%C3\%A1-competitividad-del

Unión Mundial para la Naturaleza (1999). Develando el Género. Elementos Conceptuales básicos para entender la equidad. En M. Alfaro, Develando el Género. Elementos Conceptuales básicos para entender la equidad. (pág. 31). Costa Rica.

VÁsquez, G. (2017). Repositorio tesis UNMSM - SUNEDU. Obtenido de Repositorio tesis UNMSM - SUNEDU: http://cybertesis.unmsm.edu.pe/bitstream/handle/cybertesis/6844/ Vasquez_zg.pdf?sequence $=2$ \&isAllowed $=y$ 


\section{Registro fotográfico}
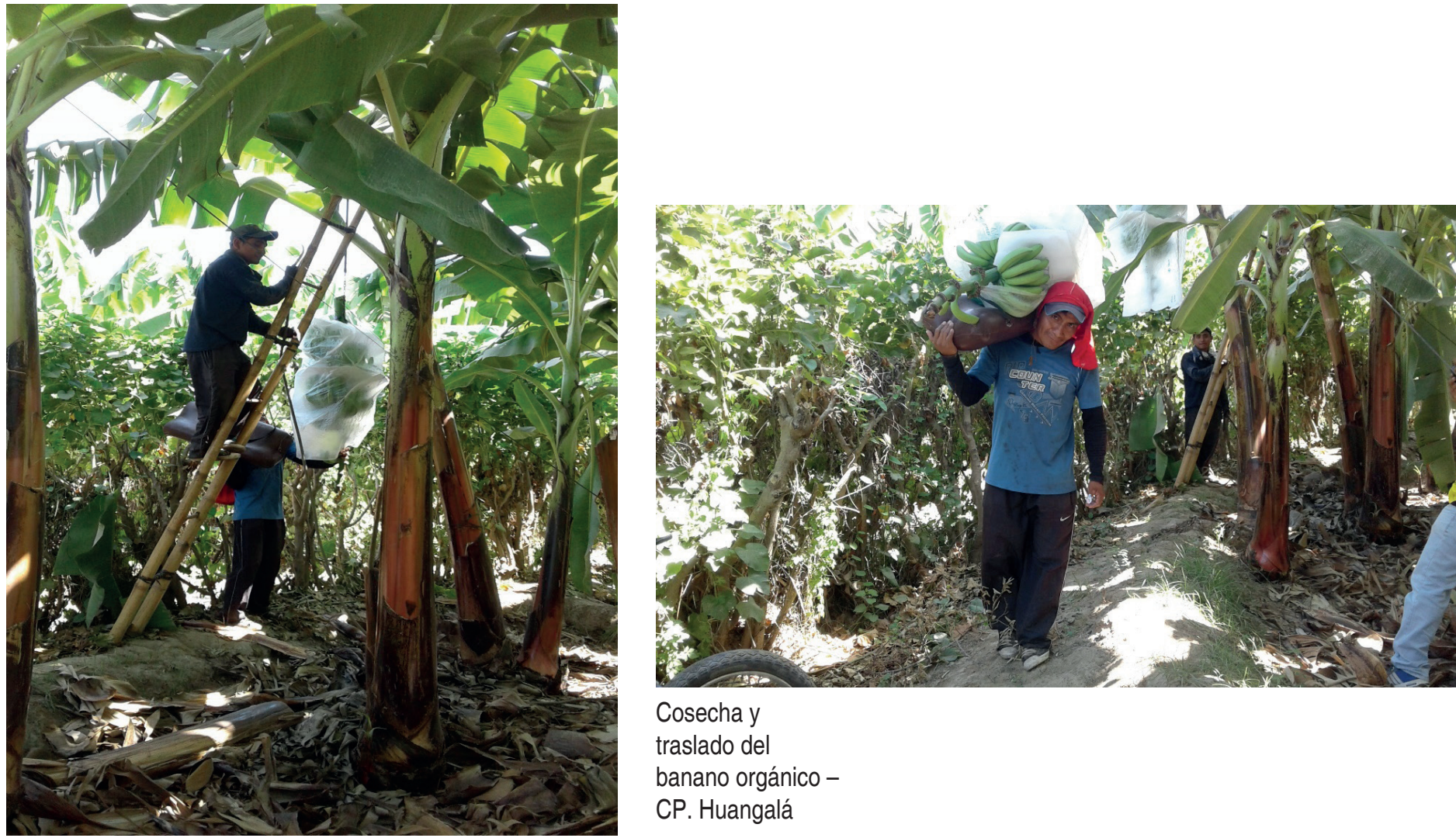

Cosecha y

traslado del

banano orgánico -

CP. Huangalá

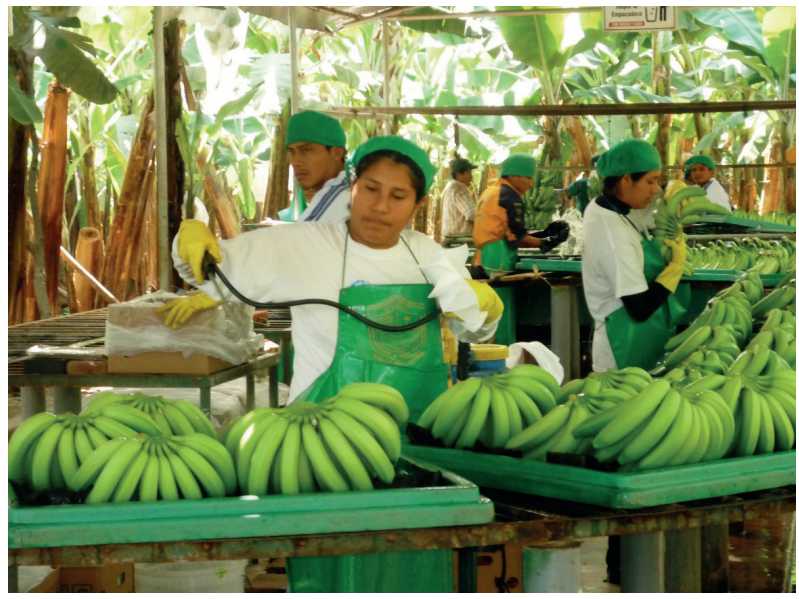

Fumigación del banano

orgánico - Empacadora del

CP. Huangalá.

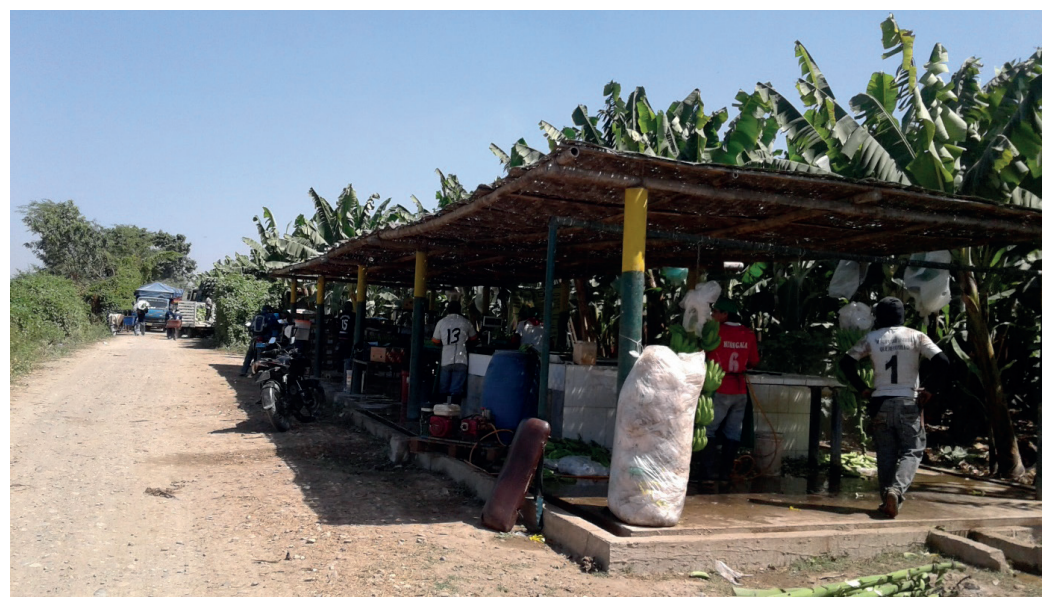

Empacadora de banano orgánico - CP.

San Vicente de Piedra Rodada 


\section{Mapas de ubicación}

Mapa de ubicación: Provincia de Sullana - Distrito de Sullana y CP. De Huangalá y San Vicente de Piedra Rodada

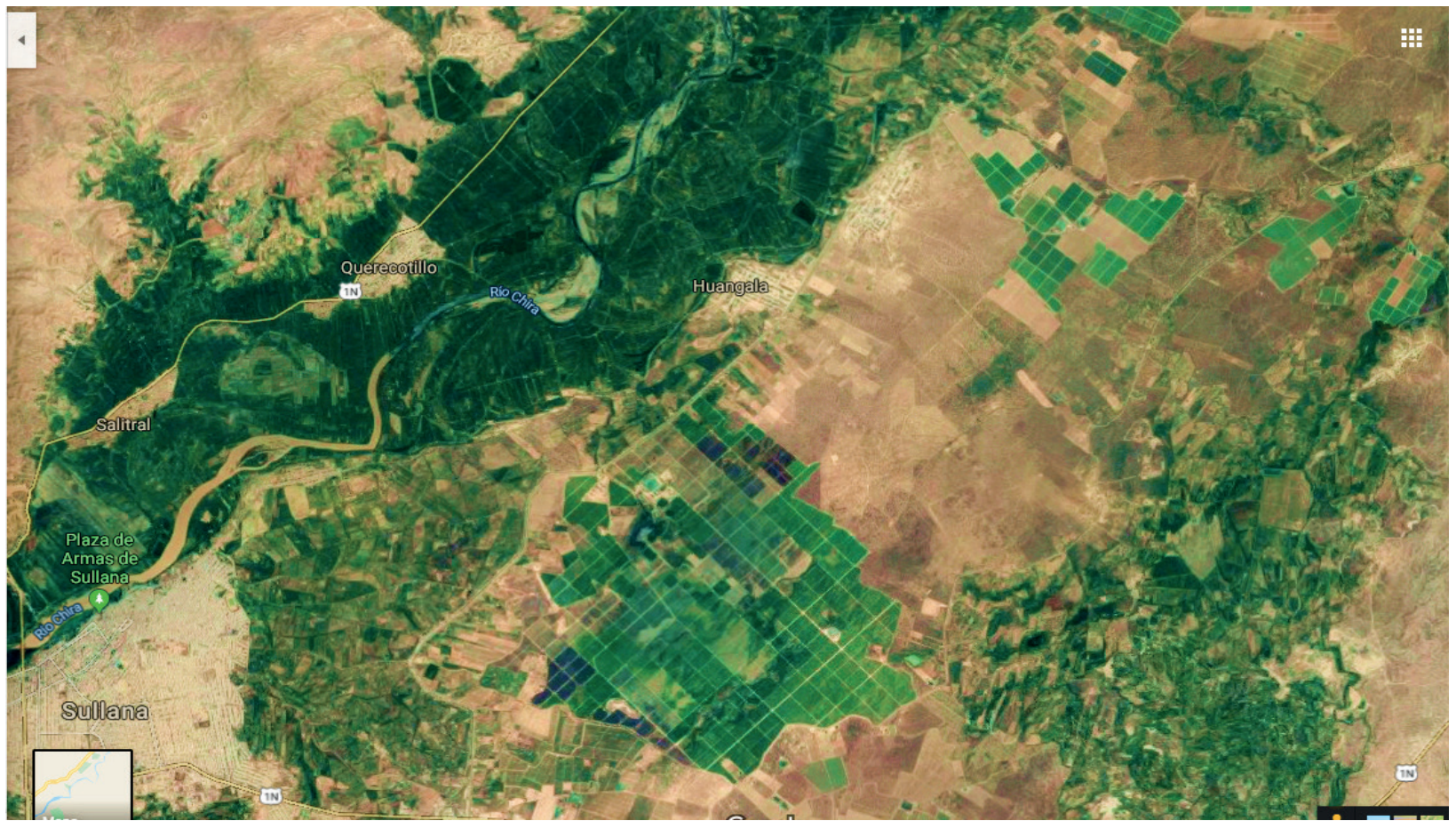

Fuente: Google - https://www.google.com/maps/place/Sullana/@-4.9143091,-80.7628398,28165m/data=!3m1!1e3!4m5!3m4!1s0x9035fbc9c03 51851:0xdcd0321c3322ccb2!8m2!3d-4.903638!4d-80.6864323

Mapa de ubicación: Centros Poblados de Huangalá y San Vicente de Piedra Rodada

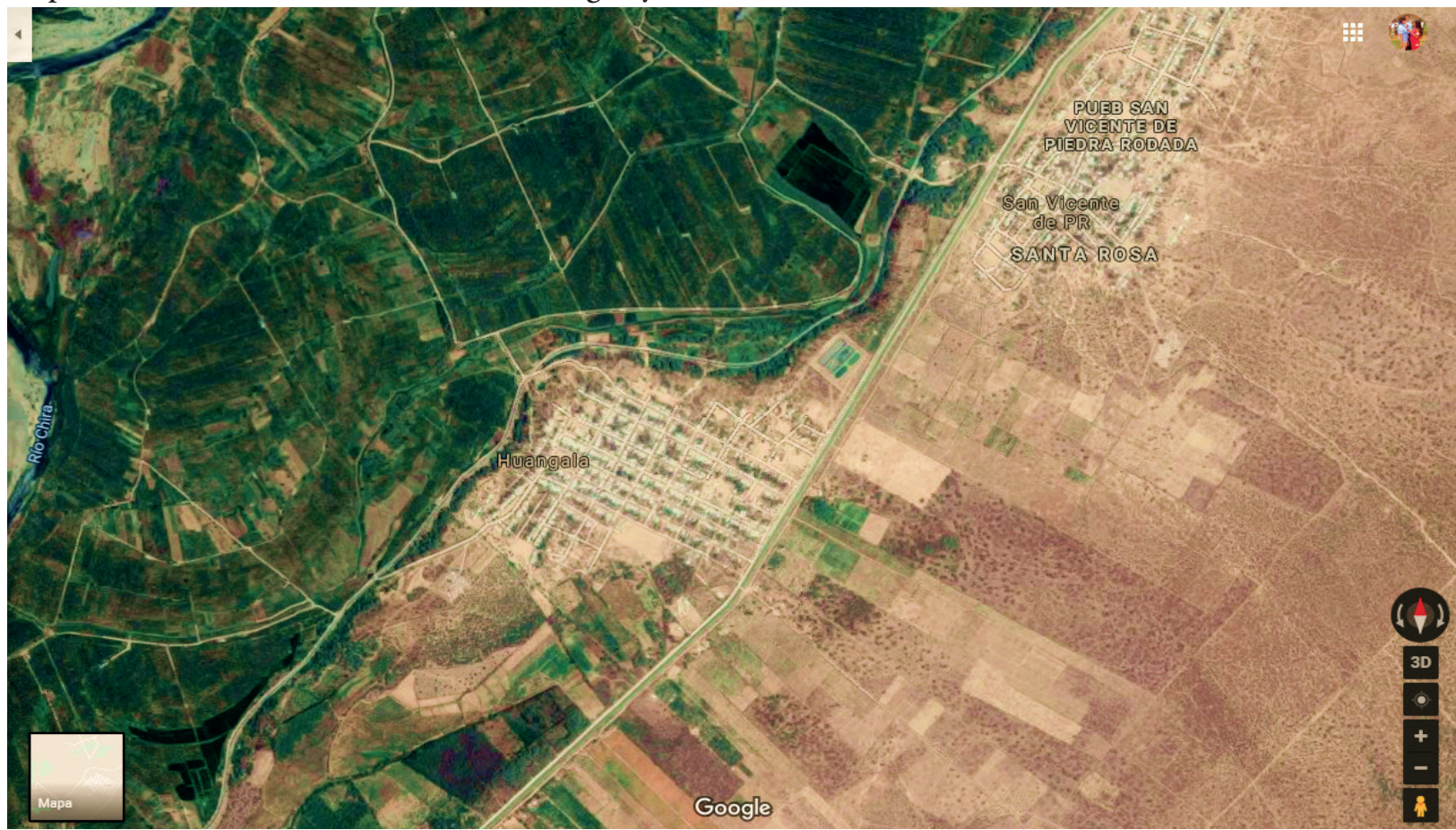

Fuente: Google - https://www.google.com/maps/search/centro+poblado+de+San+vicente+de+piedra+rodada/@-4.839533,-80.6042447,3525m/ data=!3m1!1e3 